\title{
RASIONALITAS PARAKU DALAM MANAGEMEN SISTEM IRIGASI DI JORONG SITUGAR NAGARI TANJUNG BONAI KECAMATAN LINTAU BUO UTARA ${ }^{1}$
}

\author{
Rahmi Awalina ${ }^{1}$, Eri Gas Ekaputra ${ }^{2}$, Isril Berd ${ }^{2}$ \\ ${ }^{1}$ Program Pascasarjana Teknik Pertanian, Fakultas Teknologi Pertanian, Universitas Andalas \\ ${ }^{2}$ Fakultas Teknologi Pertanian, Universitas Andalas \\ Email: rachmee85@yahoo.com
}

\begin{abstract}
ABSTRAK
Penelitian bertujuan untuk melihat paraku sebagai alat bagi air tradisional yang mampu membagi air secara rasionalitas dalam memenuhi kebutuhan air irigasi. Penelitian ini dilakukan dengan cara mengukur debit air dengan menggunakan persamaan ambang lebar yang dikorelasikan dengan kebutuhan air setiap sawah yang terairi. Hasil penelitian menunjukkan bahwa adanya hubungan antara debit pada alat bagi paraku dengan kebutuhan air sawah yang terairi. Paraku mempunyai pola pengaturan air yang sangat proporsional dengan nilai efisiensi 87,9\% dan efektifitas $84 \%$.

Kata kunci-paraku; rasionalitas; manajemen sistem irigasi
\end{abstract}

\section{PENDAHULUAN}

Pengelolaan sistem irigasi di tingkat usaha tani telah ditetapkan dalam landasan hukum yaitu Peraturan Pemerintah No. 20 Tahun 2006 tentang Irigasi. Landasan hukum tersebut, ditekankan bahwa "pengelolaan sistem irigasi tersier menjadi hak dan tanggung jawab perkumpulan petani pemakai air". Artinya, segala tanggung jawab pengembangan dan pengelolaan sistem irigasi di tingkat tersier menjadi tanggung jawab lembaga perkumpulan petani pemakai air, pada beberapa daerah dikenal dengan Mitra Cai, Subak, HIPPA, Dharma Tirta termasuk perkumpulan petani pemakai air tanah (P3AT). Untuk itu, diperlukan kelembagaan P3A yang kuat, mandiri dan berdaya sehingga pengembangan dan pengelolaan sistem irigasi dapat terlaksana dengan baik dan berkelanjutan, dan pada akhirnya mampu meningkatkan produktivitas dan produksi pertanian dalam mendukung upaya peningkatan kesejahteraan petani dan ketahanan pangan nasional. Berdasarkan paradigma pemerintah, definisi pengelolaan irigasi yang baik perlu dilakukan serangkaian kegiatan yang menyangkut semua aspek operasi dan pemeliharaan, mulai dari pengerahan tenaga untuk pembersihan, perbaikan dan penyelesaian konflik tentang pembagian air dan perencanaan untuk musim tanam berikutnya.

Kata kunci irigasi sebetulnya adalah sustainability (keberlangsungan). Definisi dari keberlangsungan adalah usaha pencarian terhadap sekumpulan kebijaksanaan dan praktek dengan keyakinan bahwa sistem irigasi akan bertahan dan berfungsi dengan baik. Keberlangsungan tidak bisa jalan kalau hampa budaya, harus ada nilai budaya yang memberi jiwa dan semangat kepada keberlangsungan tersebut. Ide dan penerapan P3A yang dimulai sejak Pelita V era Orde Baru, belum bisa mengelola irigasi secara keberlangsungan yang dimaksud (Helmi, 1992).

Belakangan ini mulai disadari pentingnya kebijakan dalam pengembangan dan pengelolaan irigasi yang sebanyak mungkin melibatkan peran petani. Sejarah membuktikan bahwa petani beririgasi di Indonesia telah berkembang sejak ratusan tahun yang lalu melalui pendekatan teknologi indigenous (tradisional) dan partisipatif. Sebagai contoh budaya petani beririgasi tersebut, antara lain, Subak di Bali, Tudang Sipulung di Sulawesi Selatan, Kapalo Banda di Sumatera Barat dan sebagainya, yang masih dilestarikan sampai sekarang.

Di Sumatera Barat, irigasi dalam konteks sustainability sebetulnya adalah peradaban lama, dengan pengelolaan berbasis kearifan lokal. Secara jamak dikenal dengan banda. Masih banyak daerah yang merawat kearifan tersebut dalam urusan pertanian. Beberapa diantaranya bisa dijumpai di Jorong Situgar Nagari Tanjung Bonai, Kecamatan Lintau Buo Utara dan Nagari Sabu, Kecamatan Batipuh. Dari penelitian sebelumnya yang telah dilakukan di Jorong Situgar Kenagarian Tanjung Bonai

\footnotetext{
${ }^{1}$ paraku adalah nama alat bagi air secara proporsional yang merupakan istilah lokal di kawasan Minangkabau daratan khususnya di Kecamatan Lintau Buo Utara dan sekitarnya. Alat ini terbuat dari kayu dan dibuat takuak untuk jalannya air sesuai dengan luas sawah dan kebutuhan air sawah yang terairi.
} 
menyebutkan bahwa alat bagi air proporsional paraku ternyata mampu membagi air secara adil dan merata dalam mengairi lahan sawah petani. Irigasi tradisional dengan teknologinya bukan hanya sekedar benda hasil karya manusia. Didalamnya tercakup berbagai kompleks ide-ide, gagasan, nilainilai, peraturan, serta komplek aktivitas kelakukan berpola dari masyarakat pendukungnya (Kurnia, 1992).

Untuk pengelolaan banda, didahului oleh konsensus. Pituah adat yang berlaku di Minangkabau menjadi pedoman dalam melahirkan kesepakatan yakni bulek aie dek pambuluah (bulat air karena pembuluh); bulek kato dek mufakaik (bulat kata karena mufakat); bulek nak bulieh digolongkan (bulat supaya boleh digelindingkan); picak nak bulieh dilayangkan. Musyawarah yang senantiasa ada dalam pengelolaan irigasi banda di Sumatera Barat bentuk partisipasi demokrasi. Kesetaraan dan musyawarah dalam pengambilan keputusan adalah asas yang terdapat dalam demokrasi. Pengambilan keputusan melalui musyawarah sebagai procedural justice akan terlaksana apabila menggunakan dialog yang dilandasi pada kesetaraan. Dialog adalah bentuk komunikasi yang rasional dan egaliter. Rasional karena menggunakan landasan berpikir kritis dan rasional dalam memecahkan permasalahan dan egaliter karena mengedepankan kesetaraan.

Meninjau irigasi tradisional diperlukan perspektif sejarah, merunut pada masa sebelum diformalkannya kelembagaan irigasi tradisional tersebut, lalu suatu yang rasionalitas menjadi kearifan bersama, dan dijadikan sistem yang ditaati bersama. Penelitian ini bertujuan untuk melihat paraku sebagai alat bagi air proporsional secara tradisional mampu membagi air secara rasionalitas dalam memenuhi kebutuhan air irigasi.

\section{METODOLOGI PENELITIAN}

\section{A. Waktu dan Tempat}

Penelitian ini dilakukan di Daerah Irigasi Gurun (Bandar Situgar), Kenagarian Tanjung Bonai, Kecamatan Lintau Buo Utara, Kabupaten Tanah Datar. Penelitian ini dilaksanakan mulai bulan April sampai dengan Juni 2017.

\section{B. Alat dan Bahan}

Alat yang digunakan yaitu: meteran untuk mengukur panjang saluran irigasi, pelampung sebagai alat ukur kecepatan aliran dan stopwatch. Bahan yang digunakan berupa data primer yakni data kondisi kelembagaan pengelola irigasi (P3A), dan data kondisi jaringan irigasi. Data sekunder yakni peta sketsa Daerah Irigasi Situgar Bandar Gurun, peta sket hasil inventarisasi alat bagi air proporsional Paraku, peta lokasi tempat penelitian, data debit, data klimatologi rata-rata 10 tahunan, data curah hujan 10 tahunan, dan data iklim.

\section{Prosedur Penelitian \\ 1. Pengumpulan data}

Data-data yang dibutuhkan dalam penelitian ini adalah data primer dan data sekunder. Data primer yang dibutuhkan adalah: data kondisi kelembagaan pengelola irigasi (P3A), data kondisi jaringan irigasi, data efisiensi irigasi, dan data efektivitas irigasi. Sedangkan data sekunder yang dibutuhkan adalah: data kuantitatif P3A, peta administrative, skema jaringan irigasi, peta sket hasil inventarisasi alat bagi air proporsional paraku, data klimatologi 10 tahunan, data curah hujan 10 tahunan, data debit paraku, data kebutuhan air irigasi, dan data iklim.

\section{Pengukuran Lebar Takuak}

Pengukuran lebar takuak alat bagi proporsional paraku, terlebih dahulu diinvetarisasi paraku yang hanya sifatnya membagi pada saluran dan paraku yang langsung ke sawah. Pengukuran lebar takuak menggunakan meteran yaitu dengan cara mengukur pada dasar takuak alat pada setiap paraku yang ada di saluran irigasi Gurun Bandar Situgar. Pengukuran lebar takuak bertujuan untuk mengetahui debit yang masuk pada masing-masing takuak.

\section{Perhitungan Debit}

Pengukuran debit bertujuan untuk melihat kondisi pengaliran air irigasi yang berfungsi untuk menganalisis apakah saluran tersebut berfungsi dengan baik, rusak ringan, sedang ataupun rusak berat. 
Pengukuran debit dilakukan di setiap saluran irigasi pada jaringan irigasi dengan cara mengalikan kecepatan aliran dengan luas penampang basah. Kecepatan aliran didapatkan dari pengukuran manual pada saluran. Pengukuran debit aliran pada saluran dengan menggunakan pelampung, didapatkan rumus:

$\mathrm{Q}=\mathrm{A} \times \mathrm{k} \times \mathrm{V}$

keterangan:

$\mathrm{Q}=$ debit aliran $\left(\mathrm{m}^{3} / \mathrm{det}\right)$

$\mathrm{V}=$ kecepatan pelampung $(\mathrm{m} / \mathrm{det})$

A $=$ luas penampang $\left(\mathrm{m}^{2}\right)$

$\mathrm{k} \quad=$ koefisien pelampung $(0.86)$

Perhitungan debit pada setiap paraku alat bagi proporsional (bila salurannya kecil) dengan cara menggunakan ambang lebar yaitu dengan persamaan sebagai berikut:

$\mathrm{Q}=1,86 \times \mathrm{B} \mathrm{x} \mathrm{H}^{3 / 2}$

keterangan:

$\mathrm{Q}=$ debit air $(1 /$ det $)$

$\mathrm{B}=$ ambang lebar $(\mathrm{m})$

$\mathrm{H}$ = tinggi air $(\mathrm{m})$

Luas penampang basah didapatkan tergantung dari bentuk salurannya. Gambar penampang melintang saluran persegi dan penampang melintang saluran trapesium dapat dilihat pada Gambar 1 dan 2.

a. Luas penampang basah bentuk empat persegi panjang

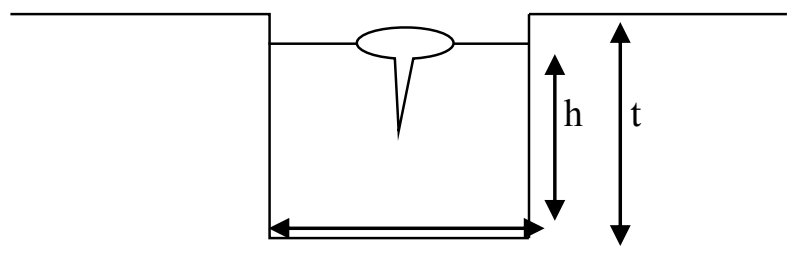

Gambar 1. Penampang melintang saluran empat persegi panjang

$\mathrm{A}=\mathrm{b} \times \mathrm{h}$

keterangan:

A = luas penampang basah $\left(\mathrm{m}^{2}\right)$

$\mathrm{b} \quad=$ lebar penampang basah $(\mathrm{m})$

$\mathrm{h} \quad=$ kedalaman air $(\mathrm{m})$

b. Luas penampang basah bentuk trapesium

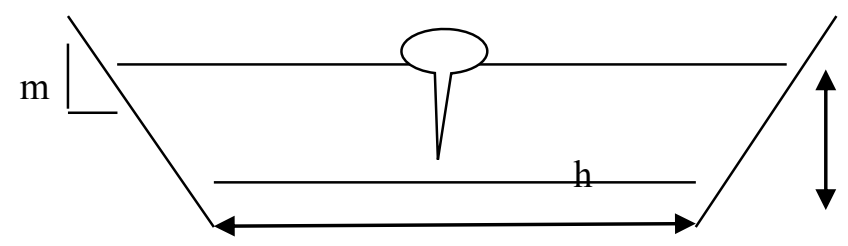

Gambar 2. Penampang melintang saluran trapesium

$\mathrm{A}=\mathrm{bh}+\mathrm{mh}^{2}$

keterangan:

A $=$ Luas penampang melintang $\left(\mathrm{m}^{2}\right)$

$\mathrm{b} \quad=$ Lebar dasar saluran $(\mathrm{m})$

$\mathrm{h} \quad=$ Kedalaman air $(\mathrm{m})$

$\mathrm{m}=$ Kemiringan dinding $(\mathrm{m} / \mathrm{m})$ 


\section{Efisiensi Irigasi}

Metode pengukuran efisiensi yang digunakan adalah masing-masing saluran irigasi dibagi menjadi tiga bagian (hulu, tengah dan hilir) pada saluran primer, sekunder dan tersier. Pada tiap bagian dihitung debit inlet dan outlet sesuai dengan persamaan (1), maka penentuan nilai efisiensi seluruh jaringan irigasi didapatkan dari nilai efisiensi pada saluran primer dikalikan nilai efisiensi saluran sekunder dan efisiensi saluran tersier. Nilai ketiga bagian tersebut ditambahkan dan dibagi tiga, sehingga didapatkan nilai efisiensi saluran. Pengelompokan nilai/tingkat efisiensi dengan harkatnya dapat dilihat pada Tabel 1. Efisiensi saluran irigasi dinyatakan dengan persamaan:

Eff $=\frac{Q \text { out }}{Q \text { in }} \times 100 \%$

keterangan:

Eff $\quad=$ efisiensi saluran (\%)

$\mathrm{Q}$ in $=$ debit pangkal saluran $\left(\mathrm{m}^{3} / \mathrm{det}\right)$

$\mathrm{Q}$ out $=$ debit ujung saluran $\left(\mathrm{m}^{3} / \mathrm{det}\right)$

Tabel 1. Hubungan Tingkat Efisiensi dengan Harkatnya.

\begin{tabular}{lc}
\hline Tingkat Efisiensi & Harkat \\
\hline$\geq 0,90$ & Baik sekali \\
$0,80-0,90$ & Baik \\
$0,70-0,80$ & Cukup \\
$0,64-0,70$ & Kurang \\
$\leq 0,64$ & Kurang sekali
\end{tabular}

Sumber: Suroso et al. (2006)

\section{Efektivitas irigasi}

Efektivitas jaringan irigasi merupakan upaya yang dilakukan untuk mencapai hasil (daya guna) dalam sistem irigasi maupun manajemen operasi dan pemeliharaan (O\&P) irigasi. Efektivitas jaringan irigasi diukur dengan menggunakan metode Indeks luas areal (IA). Pengelompokan nilai/efektivitas dengan harkatnya yang dapat dilihat pada Tabel 2 . Indeks luas areal tanam dihitung dengan persamaan:

$\mathrm{IA}=\frac{\text { Luas Aktual }}{\text { Luas Rencana }} \times 100 \%$

keterangan:

IA $=$ indeks luas areal tanam

Luas Aktual = luas tanam yang terjadi di lapangan $(\mathrm{Ha})$

Luas Rencana = luas tanam rencana $(\mathrm{Ha})$

Tabel 2. Hubungan Tingkat Efektivitas dengan Harkatnya.

\begin{tabular}{cc}
\hline Tingkat Efektivitas & Harkat \\
\hline$\geq 0,875$ & Baik sekali \\
$0,750-0,85$ & Baik \\
$0,625-0,750$ & Cukup \\
$0,500-0,625$ & Kurang \\
$\leq 0,500$ & Kurang sekali \\
\hline
\end{tabular}

Sumber: Suroso et al. (2006)

\section{HASIL DAN PEMBAHASAN}

\section{A. Gambaran Umum Daerah Penelitian}

Kecamatan Lintau Buo Utara adalah satu dari 14 kecamatan yang ada di Kabupaten Tanah Datar, Sumatera Barat. Secara geogafis, Kecamatan Lintau Buo Utara berjarak $\pm 30 \mathrm{~km}$ arah utara dari ibukota Kabupaten Tanah Datar, Batusangkar. Sementara dari Ibukota Sumatera Barat, Kota Padang, Lintau Buo Utara berjarak $\pm 135 \mathrm{~km}$. Wilayah Kecamatan Lintau Buo Utara terletak pada ketinggian 
antara 390 hingga 550 meter di atas permukaan laut (Mdpl). Memiliki luas wilayah $\pm 74,10 \mathrm{Ha}$, Lintau Buo pada tahun 2016 memiliki populasi 35.964 jiwa.

Secara kecuacaan, Lintau Buo Utara merupakan daerah bayang-bayang hujan. Curah hujan di wilayah ini rata-rata 173,77 mm/bulan. Berikut (Tabel 3) data iklim Lintau Buo selama 10 tahun mulai dari tahun 2006 hingga tahun 2015.

Tabel 3. Rekap Data Iklim (Tahun 2006 - 2015)

\begin{tabular}{|c|c|c|c|c|c|c|}
\hline Bulan & $\begin{array}{c}\text { Suhu } \\
\text { Rata-rata } \\
\left({ }^{\circ} \mathrm{C}\right) \\
\end{array}$ & $\begin{array}{c}\text { Kelembaban } \\
(\%)\end{array}$ & $\begin{array}{c}\text { Kecepatan } \\
\text { Angin } \\
(\mathrm{Km} / \mathrm{hari})\end{array}$ & $\begin{array}{c}\text { Penyinaran } \\
\text { Matahari } \\
(\%)\end{array}$ & $\begin{array}{c}\text { Eto } \\
\text { (mm/hari) }\end{array}$ & $\begin{array}{l}\text { Curah Hujan } \\
(\mathrm{mm} / \mathrm{hari})\end{array}$ \\
\hline Januari & 27.22 & 78.86 & 18.17 & 21.23 & 2.776 & 233.21 \\
\hline Februari & 27.38 & 77.29 & 18.57 & 19.64 & 2.858 & 230.09 \\
\hline Maret & 27.37 & 78.25 & 19.40 & 26.59 & 3.112 & 236.81 \\
\hline April & 27.55 & 79.19 & 16.34 & 30.14 & 2.613 & 237.96 \\
\hline Mei & 27.59 & 80.15 & 20.47 & 28.93 & 2.525 & 129.35 \\
\hline Juni & 27.42 & 78.94 & 20.43 & 19.56 & 2.016 & 95.74 \\
\hline Juli & 27.38 & 77.65 & 29.74 & 35.26 & 2.447 & 91.69 \\
\hline Agustus & 27.77 & 78.67 & 30.56 & 23.92 & 2.515 & 83.61 \\
\hline September & 27.41 & 78.79 & 27.25 & 22.65 & 2.901 & 97.92 \\
\hline Oktober & 27.38 & 79.26 & 16.20 & 27.42 & 3.073 & 166.93 \\
\hline November & 27.61 & 83.69 & 22.59 & 21.56 & 2.762 & 251.99 \\
\hline Desember & 27.47 & 80.06 & 23.09 & 23.38 & 2.812 & 229.99 \\
\hline Rata-rata & 27.46 & 79.23 & 21.90 & 25.02 & 2.701 & 173.77 \\
\hline
\end{tabular}

Berdasarkan Tabel 3 dapat dilihat bahwa suhu rata-rata bulanan yaitu $27.46{ }^{\circ} \mathrm{C}$, kelembaban rata-rata $79.23 \%$, kecepatan angin rata-rata $21.90 \mathrm{~km} /$ hari, rata-rata penyinaran matahari $25.02 \%$, ratarata evaporasi potensial (Eto) $2.701 \mathrm{~mm} /$ hari. Curah hujan maksimum terjadi pada bulan November yaitu $251.99 \mathrm{~mm} /$ bulan, sedangkan curah hujan minimum terjadi pada bulan Agustus yaitu 83.61 $\mathrm{mm} / \mathrm{bulan}$.

Menurut klasifikasi iklim Oldeman, Kecamatan Lintau Buo Utara termasuk iklim dengan tipe B karena memiliki bulan basah 7 sampai 9 kali berturut-turut. Pembagian iklim menurut Oldeman berdasarkan bulan basah terjadi (curah hujan lebih dari $200 \mathrm{~mm} /$ bulan), bulan lembab terjadi (curah hujan antara $100-200 \mathrm{~mm} / \mathrm{bulan}$ ) dan bulan kering terjadi (curah hujan kurang dari $100 \mathrm{~mm} / \mathrm{hari}$ ). Oldeman membagi tipe iklim menjadi 5 kategori yaitu A, B, C, D dan E sebagai berikut:

Tipe A: Bulan-bulan basah secara berturut-turut lebih dari 9 bulan.

Tipe B: Bulan-bulan basah secara berturut-turut antara 7 sampai 9 bulan.

Tipe C: Bulan-bulan basah secara berturut-turut antara 5 sampai 6 bulan.

Tipe D: Bulan-bulan basah secara berturut-turut antara 3 sampai 4 bulan.

Tipe E: Bulan-bulan basah secara berturut-turut kurang dari 3 bulan.

Bulan basah terjadi sebanyak 7 kali yaitu pada bulan Oktober, November, Desember, Januari, Februari, Maret dan April. Walaupun bulan basah terjadi sebanyak 7 kali berturut-turut namun kebutuhan air bagi tanaman tidak hanya bergantung pada kondisi iklim saja tapi masih banyak yang mempengaruhinya seperti sifat tanah, topografi, cara bercocok tanam, dan pertumbuhan tanaman oleh karena itu perlu adanya jadwal pemberian air agar sesuai dengan kebutuhan. Untuk mengantisipasi hal tersebut, maka irigasi sangat diperlukan dalam mengatur kebutuhan air tanaman sehingga dapat menjadi efisien dan efektif.

Mayoritas mata pencarian penduduk di Nagari Tanjung Bonai adalah bertani dengan rata-rata produksi padi 4.89 Ton/Ha. Wajar mengingat Nagari Tanjung Bonai merupakan nagari terluas di Kecamatan Lintau Buo Utara, bahkan juga di Kabupaten Tanah Datar. Nagari Tanjung Bonai memiliki luas daerah 87,04 km² dengan jumlah penduduk 11.123 jiwa dan ketinggian 515-710 Mdpl. Tanjung Bonai merupakan nagari yang menghimpun 26 jorong. Nagari Tanjung Bonai berbatasan sebelah utara dengan Nagari Halaban, Kabupaten Limapuluh Kota, sebelah selatan berbatasan dengan Nagari Balai Tangah dan Nagari Lubuk Jantan, sebelah barat berbatasan dengan Nagari Batu Bulek dan sebelah timur berbatasan dengan Nagari Lubuk Jantan dan Nagari Sumpur Kudus (BPS. Kab. Tanah Datar,2017). 
Lahan pertanian di Jorong Situgar terdiri dari lahan sawah dan lahan perladangan. Lahan perladangan banyak ditanami tanaman kakao, karet, jenis tanaman palawija dan holtikultura lainnya. Pada saat musim kemarau dimana kebutuhan air untuk lahan persawahan tidak mencukupi, maka petani Jorong Situgar lebih mengutamakan mengarap ladang untuk memenuhi kebutuhan hidup.

Kenagarian Tanjung Bonai, merupakan areal yang terletak pada upper land area atau seputaran Gunung Sago yang memakai jaringan irigasi sistim bagi air paraku. Kawasan lahan pertanian berdekatan dengan sumber air yakni Batang Ranah Batu. Ketersediaan air di Batang Ranah Batu memasok air ke banda-banda (sungai) kecil disekitarnya yakni Banda Gurun, Banda Tangah, Banda Ketek dan Banda Gadang, yang kemudian mengalirkan ke lahan pertanian. Masing - masing banda mempunyai paraku dan mengairi sawah seluas $87 \mathrm{Ha}$.

\section{B. Kebutuhan Air Irigasi dengan Menggunakan Paraku}

Kebutuhan air irigasi dapat dihitung berdasarkan luasan lahan yang diairi oleh paraku atau alat bagi air tradisional. Kebutuhan air irigasi meliputi kebutuhan air tanaman yang dicari dengan model Cropwat kemudian air yang hilang akibat perkolasi yang terjadi di lahan sawah dan efisiensi saluran irigasi (Noldi, 2015). Berdasarkan dari skema jaringan pemakaian air atau alat bagi air proporsional paraku (Bandar Gurun/Situgar) di daerah irigasi Lintau Buo Utara saat ini terdapat 31 paraku dengan ukuran takuak yang berbeda-beda sesuai dengan luas sawah atau kebutuhan air yang dialirinya. Kebutuhan air irigasi perluasan yang dialiri oleh alat bagi tradisional paraku dan debit dapat dilihat pada Tabel 4.

Tabel 4. Kebutuhan Air Irigasi dan Debit Paraku

\begin{tabular}{|c|c|c|c|c|c|c|}
\hline No & $\begin{array}{c}\text { Nama Takuak/ } \\
\text { Petak Sawah }\end{array}$ & $\begin{array}{l}\text { Luas } \\
\text { (Ha) }\end{array}$ & $\begin{array}{l}\text { Kebutuhan Air } \\
\text { Irigasi }\left(\mathrm{m}^{3} / \mathbf{s}\right)\end{array}$ & $\begin{array}{c}\text { Lebar } \\
\text { Takuak (m) }\end{array}$ & $\begin{array}{l}\text { Tinggi Air } \\
\text { (m) }\end{array}$ & $\begin{array}{l}\text { Debit } \\
\left(\mathrm{m}^{3} / \mathrm{s}\right)\end{array}$ \\
\hline & SALURAN INDUK & - & - & & & 0,04159086 \\
\hline 1 & SALURAN SEKUNDER & - & - & 1,20 & 0,05 & 0,02495 \\
\hline 2 & BAGI TERSIER (T1) & - & - & 0,80 & 0,05 & 0,01664 \\
\hline 3 & ST.T1.KW.KR.4 KR & 0,25 & 0,00018 & 0,15 & 0,015 & 0,00051 \\
\hline 4 & ST.T1.KW.KR.4 KN & 0,25 & 0,00018 & 0,15 & 0,015 & 0,00051 \\
\hline 5 & ST.T1.KW.KN.5 KR & 0,375 & 0,00027 & 0,15 & 0,015 & 0,00051 \\
\hline 6 & ST.T1.KW.KN.6 KR & 0,625 & 0,00046 & 0,55 & 0,01 & 0,00102 \\
\hline 7 & ST.T1.KW.KN.6 KN & 0,375 & 0,00027 & 0,47 & 0,01 & 0,00087 \\
\hline 8 & BAGI TERSIER (T2) KN & - & - & 0,30 & 0,03 & 0,00290 \\
\hline 9 & BAGI TERSIER (T2) TG & - & - & 0,80 & 0,08 & 0,03367 \\
\hline 10 & BAGI TERSIER (T2) KR & - & - & 0,50 & 0,05 & 0,01040 \\
\hline 11 & ST.T2. $7 \mathrm{KR}$ & 0,75 & 0,00055 & 0,47 & 0,025 & 0,00346 \\
\hline 12 & ST.T2. $7 \mathrm{KN}$ & 0,625 & 0,00046 & 0,55 & 0,025 & 0,00404 \\
\hline 13 & ST.T2. KW1. 8 TG & 1,125 & 0,00082 & 0,25 & 0,045 & 0,00444 \\
\hline 14 & ST.T2. KW1. 9 KR & 0,875 & 0,00064 & 0,35 & 0,025 & 0,00257 \\
\hline 15 & ST.T2. KW1. $9 \mathrm{KN}$ & 0,75 & 0,00055 & 0,35 & 0,025 & 0,00257 \\
\hline 16 & ST. T2. KW1. $10 \mathrm{KR}$ & 0,375 & 0,00027 & 0,07 & 0,095 & 0,00381 \\
\hline 17 & ST. T2. KW2. $11 \mathrm{KR}$ & 0,25 & 0,00018 & 0,13 & 0,01 & 0,00024 \\
\hline 18 & ST. T2. KW2. $11 \mathrm{KN}$ & 0,25 & 0,00018 & 0,13 & 0,01 & 0,00024 \\
\hline 19 & ST. T2. KW2. $12 \mathrm{KR}$ & 0,375 & 0,00027 & 0,12 & 0,015 & 0,00041 \\
\hline 20 & ST.T2. KW2. 13 KR & 0,625 & 0,00046 & 0,32 & 0,02 & 0,00168 \\
\hline 21 & ST.T2. KW2. 14 KR & 0,625 & 0,00046 & 0,40 & 0,005 & 0,00026 \\
\hline 22 & ST.T2. KW2. $14 \mathrm{KN}$ & 0,375 & 0,00027 & 0,25 & 0,005 & 0,00016 \\
\hline 23 & BAGI TERSIER (T3) KN & - & - & 0,12 & 0,05 & 0,00250 \\
\hline 24 & BAGI TERSIER (T3) TG & - & - & 0,45 & 0,05 & 0,00936 \\
\hline 25 & BAGI TERSIER (T3) KR & - & - & 0,55 & 0,05 & 0,01144 \\
\hline 26 & ST.T3. $15 \mathrm{KN}$ & 0,25 & 0,00018 & 0,12 & 0,05 & 0,00250 \\
\hline 27 & ST.T3. TG. $16 \mathrm{KR}$ & 0,25 & 0,00018 & 0,10 & 0,085 & 0,00461 \\
\hline 28 & ST.T3. TG. $16 \mathrm{KN}$ & 0,625 & 0,00046 & 0,25 & 0,03 & 0,00242 \\
\hline 29 & ST.T3. KR. $17 \mathrm{KN}$ & 0,25 & 0,00018 & 0,12 & 0,03 & 0,00116 \\
\hline 30 & ST.T3. KR. 18 KR & 0,25 & 0,00018 & 0,62 & 0,035 & 0,00755 \\
\hline \multirow[t]{2}{*}{31} & ST.T3. KR. $18 \mathrm{KN}$ & 0,5 & 0,00037 & 0,40 & 0,035 & 0,00487 \\
\hline & Jumlah & $11 \mathrm{Ha}$ & 0,00802 & & & \\
\hline
\end{tabular}

Sumber: Noldi (2015) 
Berdasarkan Tabel 4 dapat dilihat bahwa kebutuhan air irigasi tertinggi terdapat pada petak sawah ST.T2. KW1. 8 TG yaitu $0,00082 \mathrm{~m}^{3} / \mathrm{s}$ atau 8,2 liter/detik. Kebutuhan air irigasi ini sudah termasuk kehilangan air yang diakibatkan oleh perkolasi yaitu perkolasi yang terjadi senilai 2,6 $\mathrm{mm} /$ hari.

\section{Debit}

Sistem pembagian air melalui takuak tidak ditentukan oleh jumlah debit air yang masuk, melainkan seberapa besar kebutuhan masing-masing sawah. Hal ini membuktikan bahwa paraku sifatnya hanya membagi air atas porsi luas sawah yang dimiliki oleh petani. Kecilnya debit air yang masuk melalui paraku akan dibagi sama rata berdasarkan lebar takuak. Sebab, konstruksi paraku dan pemasangan paraku sifatnya tidak membendung air tapi hanya mengalirkannya sampai ke petakan sawah petani. Tujuan dari pengukuran debit pada saluran sistim pembagian air proporsional paraku adalah untuk melihat sejauh mana paraku dapat membagi air irigasi berdasarkan porsi yang dimiliki oleh petani pada debit tertentu serta melihat perbandingan pembagian air dengan lebar takuak paraku (Setiawan, 1994).

Menurut Arsyad (1976) dalam Setiawan (1994), dengan mengetahui debit air pada saluran akan dapat direncanakan pembuatan jaringan irigasi serta kebutuhan areal pertanian didalam pemakaian air irigasi. Pemakaian air irigasi yang tepat akan meningkatkan efisiensi penggunaan air irigasi sehingga dapat digunakan secara maksimal. Efisiensi irigasi dapat dipertinggi dengan jalan mengurangi tinggi penggenangan, melakukan pergiliran; yaitu pergiliran berdasarkan saluran sekunder, tersier serta pergiliran berdasarkan petak sawah dan pergiliran berdasarkan kebutuhan air bagi pertumbuhan tanaman.

Pada Tabel 4 dapat dilihat hasil dari pengukuran debit pada sistem pembagian air irigasi berbasis paraku, data yang diperoleh menyatakan bahwa debit untuk lebar takuak dipengaruhi oleh luas sawah, sedangkan alat bagi air paraku sifatnya hanya membagi air atas luas sawah yang dimiliki oleh petani. Debit yang diukur adalah paraku yang masih berfungsi mengairi petak sawah petani.

Debit pada saluran induk melewati alat bagi paraku yang sudah permanen menjadi dua bagian yaitu saluran sekunder dan bagi tersier (T1). Untuk bagi tersier (T1) ada Saluran Tersier (ST), Kuarter (KW), Kuarter Kiri (KR) dan Kuarter Kanan (KN). Dari hasil penelitian sebelumnya, pengukuran debit yang masuk ke paraku dengan menggunakan metode ambang lebar untuk kebutuhan air sawah menggunakan Model Cropwat, luas sawah yang terairi oleh Paraku di Bandar Gurun adalah $\pm 11 \mathrm{Ha}$ (Herry, 2015).

Menurut Ambler (1989), peletakan alat bagi paraku berdasarkan cabang-cabang saluran yang sifatnya membagi air disaluran utama dan yang langsung ke sawah adalah mewakili daerah yang diairi dengan sistem paraku. Hasil penelitian dari Ekaputra (1997) menunjukkan bahwa lebar ambang pintu air pada paraku mempunyai hubungan linear dengan luas areal layanannya (nilai koefisien korelasinya $=0.99$ ) hal ini menandakan bahwa alat bagi paraku merupakan alat bagi yang memperhitungkan keadilan dan pemerataan serta optimasi dalam pemakaian air. Bisa dikatakan paraku telah berfungsi sebagai alat pengontrol berbagai variabel irigasi untuk pencapaian nilai optimasi penggunaan dalam pemanfaatan sumber daya air. Di samping itu paraku hari ini, dapat meminimalisir biaya operasi irigasi, sebab tidak perlu perawatan berkala.

Sistem alat bagi air paraku telah berkontribusi dalam pemecahan masalah pembangunan khususnya dibidang irigasi dengan menemukan strategi pengelolaan air irigasi dengan menggunakan teknologi alat bagi air secara hemat yang mungkin cocok dengan lingkungan perbukitan yang ada di Sumatera Barat (Ekaputra, 1997).

Secara rasionalitas paraku dapat membagi air secara efisien dan efektif pada lahan sawah petani secara merata, karena sistem paraku mudah dikontrol dan dikendalikan pada setiap bangunan pembaginya. Di samping itu nilai-nilai yang terdapat pada paraku menjadikan setiap pemakai air untuk bisa selalu mempunyai sifat tenggang rasa seperti bak pepatah minang "baraia sawah diateh, lambok sawah dibawah" (berair sawah di atas, basah sawah di bawah). Artinya aksesibilitas sawah (atas) terhadap air tidak otomatis mutlak mengakses air irigasi, melainkan hanya memakai secukupnya. Sementara sawah yang agak jauh (bawah) dari saluran irigasi berbasis paraku, mendapatkan air secukupnya, bisa dari limpahan air setelah melewati sawah terdekat saluran irigasi atau langsung melalui alokasi dari takuak. Sistem paraku yang berlaku di Situgar berjalan berdasarkan tatanan sosial 
yang mengedepankan musyawarah dengan tuo banda sebagai orang yang dituakan atau paling dihormati.

\section{Efisiensi Irigasi}

Pengukuran efisiensi saluran irigasi Bandar Gurun/Situgar hanya dilakukan pada saluran primer dengan nilai pengukuran $87,9 \%$, karna pada saluran sekunder dan tersier jarak antara saluran sangat dekat sehingga untuk melakukan pengukuran efisiensi irigasi saluran sangatlah sulit. Nilai efisiensi saluran primer pada jaringan irigasi Bandar Gurun/ Situgar tergolong cukup baik yaitu $87.9 \%$. Hal ini menandakan bahwa efisiensi pemakaian air dalam kaitannya dengan keberlanjutan pemanfaatan sumberdaya air pada irigasi tradisional tidak kalah bila dibandingkan dengan irigasi yang dibangun oleh pemerintah. Paraku merupakan perwujudan dari pengetahuan lokal dimana aspek optimasi pemanfaatan air irigasi berada pada tingkat yang cukup optimal. Hal tersebut menandakan bahwa azas proporsional antara lebar pintu air dengan luas areal pelayanannya dan kinerja irigasinya sudah cukup memadai.

\section{E. Efektivitas Irigasi}

Tingkat efektivitas irigasi merupakan upaya yang dilakukan untuk mencapai hasil yang diperoleh. Pada Tabel 10 dapat diketahui nilai efektivitas irigasi Bandar Gurun/Situgar adalah $84 \%$. Menurut Suroso et al (2006), menyatakan bahwa harkat nilai efektivitas $\geq 50 \%$ digolongkan baik. Dengan begitu pengelolaan irigasi secara tradisional yang dilakukan di Situgar terbukti tidak kalah lebih baik dengan pengelolaan irigasi secara modern dari sisi efektivitas. Sistem paraku nyatanya menjadi pola pengaturan air yang sangat proporsional, mengairi sawah yang ada di sepanjang jaringan tersebut. Nilai efektivitas irigasi dapat dilihat pada Tabel 5.

Tabel 5. Nilai Efektivitas Irigasi

\begin{tabular}{clccc}
\hline No. & Saluran Petak Tersier & Luas Potensial (Ha) & Luas Sawah Berigasi & Nilai Efektivitas \\
\hline 1 & ST.T1.KW.KR. 4KR & 0.25 & 0.2 & 0.8 \\
2 & ST.T1.KW.KR.4 KN & 0.25 & 0.2 & 0.8 \\
3 & ST.T1.KW.KN.5 KR & 0.375 & 0.25 & 0.67 \\
4 & ST.T1.KW.KN. 6 KR & 0.625 & 0.5 & 0.8 \\
5 & ST.T1.KW.KN.6 KN & 0.375 & 0.25 & 0.67 \\
6 & ST.T2.7 KR & 0.75 & 0.5 & 0.67 \\
7 & ST.T2.7 KN & 0.625 & 0.5 & 0.8 \\
8 & ST.T2.KW1.8 TG & 1.125 & 0.975 & 0.87 \\
9 & ST.T2.KW1.9 KR & 0.875 & 0.75 & 0.86 \\
10 & ST.T2. KW1.9 KN & 0.75 & 0.25 & 0.33 \\
11 & ST.T2. KW1. 10 KR & 0.375 & 0.35 & 0.93 \\
12 & ST.T2. KW2. 11 KR & 0.25 & 0.2 & 0.8 \\
13 & ST.T2.KW2. 11 KN & 0.25 & 0.2 & 0.8 \\
14 & ST.T2.KW2. 12 KR & 0.375 & 0.325 & 0.87 \\
15 & ST.T2.KW2. 13 KR & 0.625 & 0.575 & 0.92 \\
16 & ST.T2.KW2. 14 KR & 0.625 & 0.6 & 0.96 \\
17 & ST.T2.KW2.14 KN & 0.375 & 0.35 & 0.93 \\
18 & ST.T3.15 KN & 0.25 & 0.2 & 0.8 \\
19 & ST.T3. TG. 16 KR & 0.25 & 0.2 & 0.8 \\
20 & ST.T3.TG. 16 KN & 0.625 & 0.575 & 0.92 \\
21 & ST.T3.KR. 17 KN & 0.25 & 0.2 & 0.8 \\
22 & ST.T3.KR. 18 KR & 0.25 & 0.2 & 0.8 \\
23 & ST.T3.KR. 18 KN & 0.5 & 0.25 & 0.5 \\
\hline & Rata- rata & & & $\mathbf{0 . 8 4 1}$ \\
\hline
\end{tabular}

Sumber: Noldi (2015) 


\section{KESIMPULAN}

Sistem paraku bisa menjadi pola pengaturan air yang sangat proporsional dengan nilai efisiensi $87,9 \%$ dan efektifitas $84 \%$. Cara pendistribusian air ini dirasakan petani sangat efisien dan tidak ada yang merasa dirugikan. Sistem paraku telah memastikan kebutuhan air irigasi, baik pada musim hujan maupun musim kemarau terpenuhi di Situgar.

\section{DAFTAR PUSTAKA}

Ambler, J. 1989. Mutiara Terpendam, Lokakarya III Penelitian Irigasi Tradisional Pusat Studi Irigasi Universitas Andalas Padang.

Badan Pusat Statistik Kabupaten Tanah Datar, "Lintau Buo Utara Dalam Angka 2017”.

Ekaputra, Erigas. 1997. Dukungan Sistem Irigasi Dalam Pengembangan SRI. Universitas Andalas. Padang

Helmi dan Ambler, J.S. 1990. Pengembangan Irigasi Kecil dalam Konteks Wilayah Sungai. Pengalaman Sumatera Barat dan Bali. PSI Unand.

Kurnia, Ganjar. 1992. Pemilihan Teknologi Irigasi. Romantisme Budaya, Tantangan Masa Depan dan Pendekatan Partisipatif. Jakarta: LP3ES

Noldi, Herry. 2015. Hubungan Debit Air Pada Alat Bagi Proporsional Paraku Terhadap Kebutuhan Air Sawah Di Desa Situgar Kecamatan Lintau Buo Utara. Skripsi. Fakultas Teknologi Pertanian Universitas Andalas. Padang.

Pemerintah Republik Indonesia. 2006. Peraturan Pemerintah Republik Indonesia No. 20 Tahun 2006 tentang Irigasi. Pemerintah Republik Indonesia. Jakarta.

Setiawan. 1994. Hubungan Lebar Takuak Alat Air Proporsional Paraku terhadap Luas Sawah yang Terairi di Desa Situgar. Skripsi. Fakultas Pertanian. Universitas Andalas. Padang

Suroso, Nugroho, dan P. S. Pamuji. 2006. Evaluasi Kinerja Jaringan Irigasi Banjaran Untuk Meningkatkan Efektifitas dan Efisiensi Pengelolaan Air Irigasi. Dinamika Teknik Sipil 